\title{
Circ-SMARCA5 suppresses progression of multiple myeloma by targeting miR-767-5p
}

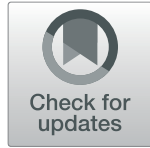

Haiyan Liư ${ }^{\dagger}$ Yan $\mathrm{Wu}^{\dagger}$, Shunye Wang, Jie Jiang, Chenlu Zhang, Yijing Jiang, Xingfeng Wang, Lewen Hong and Hongming Huang ${ }^{*}$ (1)

\begin{abstract}
Background: We aimed to investigate the correlation of Circ-SMARCA5 with disease severity and prognosis in multiple myeloma (MM), and its underlying mechanisms in regulating cell proliferation and apoptosis.

Methods: Bone marrow samples from 105 MM patients and 36 healthy controls were collected for Circ-SMARCA5 expression measurement. And the correlation of Circ-SMARCA5 expression with patients' characteristics and survival was determined. In vitro, the effect of Circ-SMARCA5 on MM cell proliferation and apoptosis was evaluated by altering Circ-SMARCA5 expression through transfection. Rescue experiments and luciferase assay were further performed to explore the mechanism of Circ-SMARCA5 as well as its potential target miR-767-5p in regulating MM cell activity.
\end{abstract}

Results: Circ-AMARCA5 was downregulated in MM and presented a good value in distinguishing MM patients from controls and it was also negatively correlated with Beta-2-microglobulin ( $\beta 2-M G)$ level and International Staging System (ISS) stage. Additionally, Circ-SMARCA5 high expression was associated with higher CR as well as better PFS and OS. As for in vitro experiments, Circ-SMARCA5 expression was lower in MM cell lines compared with normal cells, and Circ-SMARCA5 overexpression inhibited cell proliferation but promoted cell apoptosis in RPMI8226 cells. Rescue experiments disclosed that the effect of Circ-SMARCA5 on cell activity was attenuated by miR-767-5p, and luciferase reporter assay revealed direct binding between Circ-SMARCA5 and miR-767-5p.

Conclusions: Circ-SMARCA5 is downregulated and correlated with lower $\beta 2-M G$ level and ISS stage as well as better prognosis in MM patients, and it inhibits proliferation but promotes apoptosis of MM cells via directly sponging miR-767-5p.

Keywords: Circ-SMARCA5, MM, Prognosis, miR-767-5p, Proliferation, Apoptosis

\section{Background}

Multiple myeloma (MM), also called plasma cell myeloma, is a hematological malignancy characterized by proliferation of malignant monoclonal plasma cells, and its clinical manifestations include multiple bone destruction, pathological fracture, hypercalcemia, anemia, renal dysfunction and so on [1]. MM is the second most common hematological malignancy that ranks after nonHodgkin's lymphoma and is age-related, suggesting that with the population aging, the incidence of MM will greatly increase in the future [2]. Similar to other

\footnotetext{
* Correspondence: hhm_huanghongming@163.com

${ }^{+}$Haiyan Liu and Yan Wu contributed equally to this work.

Department of Hematology, Affiliated Hospital of Nantong University, 20 Xisi Road, Nantong 226001, China
}

hematological malignancies, the common therapeutic methods for MM include chemotherapy, targeted therapy, immunotherapy and hematopoietic stem cell transplantation, while the treatment efficacy is subject to relapse of disease and refractoriness to treatments, leading to poor survival in most of the MM patients [3]. Therefore, exploring more potential targets is necessary for development of new therapies and improving patients' prognosis in MM.

Non-coding RNAs, a category of RNA molecules not translated into proteins, are widely abundant in human genome and engage in numerous cellular processes including transcription, post-transcriptional modification and signal transduction [4]. Circular RNAs (CircRNAs) comprise a class of non-coding RNAs whose $3^{\prime}$ and 5' 
ends are joined together to form a covalently closed loop [5]. Benefiting from the structure, circRNAs are resistant to exonuclease-mediated degradation and are more stable compared with linear RNAs [6]. Based on evidence from the past decades, circRNAs play critical roles in gene regulation by sponging micro RNAs (miRNAs) and regulating protein translation, thereby involve in pathogenesis of various diseases, and their expression patterns and mechanisms in some solid tumors have been revealed [7]. As for hematological malignancies, circRNAs participate in development and progression of diseases and serve as valuable biomarkers for diagnosis and prognosis in patients, whereas little is known with respect to circRNAs in MM [8-10].

CircRNA SWI/SNF-related matrix-associated actindependent regulator of chromatin subfamily A member 5 (Circ-SMARCA5) is encoded by SMARCA5 gene that is located on chromosome 4 (location: NC_000004.12 $(143,513,463 . .143557489))$ [11]. Circ-SMARCA5 is previously shown to participate in carcinogenesis by inhibiting cell proliferation, migration and invasion in several solid tumors including hepatocellular carcinoma and cervical cancer [12-14]. Whereas in hematological malignancies, the role of Circ-SMARCA5 is unknown. One previous study reports that Circ-SMARCA5 is involved in the regulation of cell cycle and alterations of chromatin structures, and dysregulation of SMARCA5 gene is presented in $\mathrm{CD} 34+$ hematopoietic progenitors of hematological malignancy, and we speculated that CircSMARCA5 might participate in etiology and work as a potential biomarker of MM, a typical hematological malignancy $[11,15]$. Therefore, the purpose of this study was to investigate the correlation of Circ-SMARCA5 with disease severity and prognosis in MM patients as well as its underlying mechanisms in regulating cell proliferation and apoptosis in MM cells.

\section{Method \\ Participants}

One hundred and five de novo MM patients treated at the Affiliated Hospital of Nantong University between Jan 2015 and Dec 2016 were consecutively enrolled in this study. The inclusion criteria were: (1) newly diagnosed as MM according to 2014 International Myeloma Working Group (IMWG) updated criteria for the diagnosis of multiple myeloma; (2) age above 18 years old; (3) able to be regularly followed up; (4) life expectancy over 12 months. The exclusion criteria were as follows: (1) relapsed/refractory MM; (2) received stem cell transplantation (SCT), chemotherapy, radiotherapy or other systematic treatments before enrollment; (3) with a history of solid tumors or hematological malignancies other than MM; (4) pregnant/lactating women. In addition, there were 36 healthy bone marrow donors being recruited as controls during the same period. The present study was approved by the Ethics Committee of the Affiliated Hospital of Nantong University, and all participants provided written informed consents.

\section{Baseline data collection}

After enrollment, baseline characteristics were collected from all patients, which included: information of age, gender, immunoglobulin subtype, hemoglobin $(\mathrm{Hb})$, calcium, serum creatinine (Scr), albumin (ALB), Beta-2microglobulin ( $\beta 2-\mathrm{MG}$ ), Durie-Salmon Stage, the International Staging System (ISS) Stage, bone lesion, lactate dehydrogenase (LDH) and cytogenetics abnormality. Durie-Salmon Stage and ISS Stage were assessed according to the Durie-Salmon Criteria and ISS Criteria respectively [16, 17], and cytogenetics abnormalities were analyzed by fluorescence in situ hybridization (FISH).

\section{Sample collection and Circ-SMARCA5 detection}

Bone marrow samples of all patients were collected prior to initiation of therapy, and bone marrow samples of controls were also obtained after enrollment. Mononuclear cells were separated from bone marrow by gradient density centrifugation, then plasma cells were purified using CD138-coated magnetic beads according to the manufacturer's instructions (Miltenyi Biotec, Germany) to ensure greater than $90 \%$ plasma cell purity. Subsequently, Circ-SMARCA5 expression was determined by quantitative polymerase chain reaction (qPCR) assay.

\section{Treatment and assessment}

All patients received induction therapies after enrollment, and the selections of chemotherapy regimens entirely depended on patients' willingness and disease conditions. Fourty-eight patients received conventional chemotherapy, 36 patients underwent bortezomib-based regimen and 21 received immunomodulatory drug-based regimen, details were as follows: 26 treated with VAD regimen (doxorubicin/vincristine/dexamethasone); 22 treated with DVD regimen (liposomal doxorubicin/ vincristine/dexamethasone); 36 treated with $\mathrm{BCD}$ regimen (bortezomib/cyclophosphamide/dexamethasone), 21 treated with MPT regimen (melphalan/prednisone/thalidomide). After induction treatment, 31 patients underwent autologous SCT, and others received maintenance therapies or repeated induction regimens according to the response to induction treatment. The treatment responses including complete response (CR), very good partial response (VGPR), partial response (PR) were assessed according to the IMWG criteria [18], and the overall response rate (ORR) was defined as the percentage of patients with the achievement of CR, VGPR or PR. All MM patients were regularly followed up to 
$2017 / 12 / 31$, and the median follow-up duration was 24.0 months (range: 5.0-36.0 months). Furthermore, progression free survival (PFS) and overall survival (OS) were calculated, which were defined as: PFS, the duration from the treatment to disease progression or death; OS, the duration from the treatment to the death.

\section{Cells culture}

In order to further explore the role of Circ-SMARCA5 in $\mathrm{MM}$ etiology, cells experiments were subsequently performed. Wild type MM cell lines (NCI-H929, RPMI8226, U226, OPM2 and JJN3) were purchased from Chinese Academy of Sciences (Beijing, China) or kindly given by Shanghai Jiaotong University (Shanghai, China), and normal plasma cells were isolated from bone marrow of healthy donors using CD138-coated magnetic beads (Miltenyi Biotec, Germany) as normal control. NCI-H929, RPMI8226, U226 and OPM2 cells were cultured in 90\% RPMI-1640 medium (Gibco, USA) (containing $1.5 \mathrm{~g} / \mathrm{L} \mathrm{NaHCO}_{3}, 2.5 \mathrm{~g} / \mathrm{L}$ glucose and $0.11 \mathrm{~g} / \mathrm{L}$ sodium pyruvate) supplemented with $10 \%$ fetal bovine serum (FBS) (Gibco, USA); JJN3 cells were cultured in 40\% DMEM medium (Gibco, USA) and 40\% IMEM medium (Gibco, USA) supplemented with $20 \%$ FBS (Gibco, USA). All cells were incubated at $37^{\circ} \mathrm{C}$ under $95 \%$ air and $5 \% \mathrm{CO}_{2}$ condition.

Measurement of Circ-SMARCA5 in MM cell lines and normal plasma cells.

The qPCR was performed to detect the expression of Circ-SMARCA5 in wild-type MM cell lines: NCI-H929, RPMI8226, U226, OPM2 and JJN3, and normal plasma cells.

\section{Transfection, groups and followed measurements in RPMI8226 cells}

Blank overexpression, Circ-SMARCA5 overexpression, blank shRNA and Circ-SMARCA5 shRNA plasmids were constructed by Shanghai GenePharma Bio-Tech Company (Shanghai, China), and then transfected into RPMI8226 cells as NC (+), Circ (+), NC (-) and Circ (-) groups. Then in each group, $\mathrm{qPCR}$ was performed to measure Circ-SMARCA 5 expression at $24 \mathrm{~h}$, CCK 8 was performed to measure cell proliferation at $0 \mathrm{~h}, 24 \mathrm{~h}, 48 \mathrm{~h}$ and $72 \mathrm{~h}, \mathrm{AV} / \mathrm{PI}$ was performed to measure cell apoptosis rate at $72 \mathrm{~h}$, and Western Blot was performed to measure apoptotic markers Cleaved Caspase 3 and Bcl-2 expressions at $72 \mathrm{~h}$ post transfection. The detailed procedure of each detection was described in the following subsections.

\section{Validation in $\mathrm{NCl}-\mathrm{H} 929$ cells}

In order to validate the effect of Circ-SMARCA5 on cell proliferation and apoptosis, the transfections of blank overexpression, Circ-SMARCA5 overexpression, blank
shRNA and Circ-SMARCA5 shRNA plasmids were repeated in NCI-H929 cells, as well as qPCR at $24 \mathrm{~h}$ for detection of Circ-SMARCA5, CCK8 at $0 \mathrm{~h}, 24 \mathrm{~h}, 48 \mathrm{~h}$ and $72 \mathrm{~h}$ for cell proliferation measuement, AV/PI at 72 $\mathrm{h}$ for measurement of cell apoptosis, and measurement of apoptotic markers Cleaved Caspase 3 and Bcl-2 expressions at $72 \mathrm{~h}$ post transfection by Western Blot.

\section{Target miRNAs prediction and their measurement}

Potential target miRNAs of Circ-SMARCA5 in MM were predicted using Circular RNA Interactome database (https://Circinteractome.nia.nih.gov/) and miRanda database (http://www.microrna.org/microrna/home.do), and miR-561, miR-616 as well as miR-767-5p were selected for validation. The following $\mathrm{qPCR}$ was performed to measure their expressions at $24 \mathrm{~h}$ post transfection in Control (+), SMARCA5 (+), Control (-) and SMARCA5 $(-)$ groups.

\section{Regulation of miR-767-5p by circ-SMARCA5 in several MM cell lines}

In order to further validate the regulation of miR-767-5p by circ-SMARCA5 in MM, blank overexpression, CircSMARCA5 overexpression, blank shRNA and CircSMARCA5 shRNA plasmids were transfected into NCIH929, U226, OPM2 and JJN3 cell lines, and miR-767-5p was detected at $24 \mathrm{~h}$ post transfection by qPCR.

\section{Rescue experiment in RPMI8226 cells}

In order to explore the underlying mechanism of CircSMARCA5 on regulating cell functions in MM cells, rescue experiment was then conducted. Blank overexpression, miR-767-5p overexpression, Circ-SMARCA5 overexpression, and miR-767-5p overexpression \& CircSMARCA5 overexpression plasmids were constructed by Shanghai GenePharma Bio-Tech Company (Shanghai, China) and then transfected into RPMI8226 cells as Control (+), miR-767 (+), SMARCA5 (+), and SMARCA5 $(+) / \mathrm{miR}-767(+)$ groups. Then in each group, qPCR was performed to measure miR-767-5p and CircSMARCA5 expressions at $24 \mathrm{~h}$, CCK8 was performed to measure cell proliferation at $0 \mathrm{~h}, 24 \mathrm{~h}, 48 \mathrm{~h}$ and $72 \mathrm{~h}$, $\mathrm{AV} / \mathrm{PI}$ was performed to measure cell apoptosis rate at $72 \mathrm{~h}$, and Western Blot was performed to measure apoptotic markers Cleaved Caspase 3 and Bcl-2 expressions at $72 \mathrm{~h}$ post transfection. The detailed procedure of each detection was described in the following subsections.

\section{Luciferase reporter assay}

In order to further validate the interaction between Circ-SMARCA5 and miR-767-5p, luciferase reporter assay was subsequently conducted as follows: (1) the RPMI8226 cells were digested and inoculated on a culture plate and left in 5\% $\mathrm{CO} 2$, humidity saturated 
incubator $\left(37^{\circ} \mathrm{C}\right)$ over night. (2) When cell density exceeded 70\%, co-transfecting the cells with CircSMARCA5 wild type/ mutant type luciferase reporter plasmids and miR-767-5p overexpression/control plasmids. Reporter plasmids and overexpression plasmids were constructed by Shanghai GenePharma Bio-Tech Company (Shanghai, China). (3) At $24 \mathrm{~h}$ after transfection, the culture solution was removed and the cells were washed with cold PBS. (4) Add $350 \mu$ l pre-cooled harvest buffer into each culture dish and the cells were lysed at $4{ }^{\circ} \mathrm{C}$ or on ice for 10 mins. (5) Centrifuge for $5 \mathrm{~s}$ at $12,000 \mathrm{rpm}$. Transfering the supernatant to a new tube and discard the pelleted cell debris. (6) $5 \mathrm{ml}$ microcentrifuge tubes were prepared by adding $100 \mu \mathrm{l}$ of reactant solution of ATP buffer mixed with luciferin buffer (in ratio of 1:3.6) to each tube. (7) $100 \mu$ l of cell lysate supernatant from step 5 was added into each of the microcentrifuges prepared in step 6, blending quickly and read the absorbance value on a luminometer. (8) Ensure to read the absorbance value of all samples with the same procedure, then measured the activity of LacZ from the rest of the cell lysate and used it as an internal reference to correct the readings of luciferase.

\section{qPCR}

Total RNA was extracted using TRIzol reagent (Invitrogen, USA) and then applied for the synthesis of cDNA using PrimeScript ${ }^{\mathrm{Ts}}$ RT reagent Kit (with random primers for Circ-SMARCA5) (TAKARA, Japan). Following that, cDNA was used for qPCR with SYBR Green kit (TaKaRa, Japan). Amplification of PCR was conducted under the following condition: $95^{\circ} \mathrm{C}$ for $3 \mathrm{~min}, 40$ cycles of $95^{\circ} \mathrm{C}$ for $5 \mathrm{~s}, 61^{\circ} \mathrm{C}$ for $10 \mathrm{~s}$, and then $72{ }^{\circ} \mathrm{C}$ for $30 \mathrm{~s}$. The result was calculated using $2^{-\Delta \Delta C t}$ method and glyceraldehyde-3-phosphate dehydrogenase (GAPDH) was used as an internal reference. The primers used in qPCR were listed in Additional file 1: Table S1.

\section{Western blot}

After lysing with RIPA lysis buffer (Thermo Scientific, USA), RPMI8226 cells were centrifuged, then total protein concentration was measured using $\mathrm{BCA}^{\mathrm{sm}}$ protein assay kit (Pierce, USA). Electrophoresis was used for separating proteins on sodium dodecyl sulfatepolyacrylamide (SDS) gel. Subsequently, PVDF membrane (Millipore, USA) was used to transfer proteins and then blocked with 5\% non-fat dried milk in PBST for $1 \mathrm{~h}$ at room temperature. After incubation with primary antibodies, the PVDF membrane was finally incubated with the secondary antibody. ECL advanced Western blot analysis detection kit (BD, USA) was then used to visualize the bands indicating the abundance of proteins. The grey intensity was measured using Image $(\mathrm{NIH}$,
USA). The antibodies used in Western Blot were listed in Additional file 2: Table S2.

\section{CCK8}

Ten ul CCK-8 (Dojindo, Japan) and 90 ul medium were added to each group of RPMI8226 cells, then the cells were incubated at $37^{\circ} \mathrm{C}$ under $95 \%$ air $+5 \% \mathrm{CO} 2$. Cell proliferation ability was presented by optical density (OD) value, which was measured using a microplate reader (BioTek, USA).

\section{Av/pi}

RPMI8226 cells were digested using pancreatin and washed with phosphate buffer solution, then suspended in blinding buffer (100 ul). 10 ul AV (Invitrogen, USA) was subsequently added and the cells were left on ice for 15 min in dark. Following that, 5 ul PI (Invitrogen, USA) was added and the apoptosis rate was analyzed by flow cytometry (FCM) (Becton Dickinson, USA).

\section{Statistics}

Statistical analysis was performed using SPSS 22.0 software (IBM, USA), and figures were made with the use of GraphPad Prism 7.00 software (GraphPad Software Inc., USA). Count data were expressed as count (percentage); Continuous data were described as mean \pm standard deviation (clinical data) or mean \pm standard error (experimental data) if normally distributed, and as median (25th-75th quantiles) if not normally distributed. Comparison was determined by Chi-square test, $t$ test or Wilcoxon rank sum test. Receiver operating characteristic (ROC) curve was used to evaluate the ability of CircSMARCA5 relative expression to discriminate between MM patients and controls. Survival curves were made using the Kaplan-Meier method and significant differences between the curves were determined by log-rank test. Univariate and multivariate logistic regression analyses with Forward Stepwise (Conditional) method were performed to assess the predictive factors of CR; univariate and multivariate Cox's proportional hazards regression analyses with Forward Stepwise (Conditional) method were performed to determine the factors affecting PFS and OS. $P$ value $<0.05$ was considered as significant.

\section{Results}

\section{Patients' baseline characteristics}

One hundred-and five MM patients with mean age $59.8 \pm 9.1$ years were enrolled, and among which 65 $(61.9 \%)$ were males and $40(38.1 \%)$ were females. As to the disease staging, the numbers of patients with DurieSalmon stage I, II, and III were 4 (3.8\%), 49 (46.7\%) and $52(49.5 \%)$ respectively. Additionally, there were 24 (22.9\%), $36(34.3 \%)$ and $45(42.8 \%)$ patients with ISS 
stage I, II, and III respectively. Other detailed characteristics were listed in Table 1.

\section{Circ-SMARCA5 relative expression in MM patients}

The median Circ-AMARCA5 relative expression was $0.778(0.377-1.421)$ in MM patients, which was lower than that in control group $(1.407(0.864-2.763))(P<$ 0.001) (Fig. 1a). ROC curve illustrated that CircAMARCA5 was of good value in distinguishing MM patients from the controls with area under curve (AUC) of 0.714 (95\%CI: 0.614-0.814). The sensitivity and specificity at the best cut-off point (the point where the largest sum of sensitivity and specificity occurred) were 93.3

Table 1 Baseline characteristics of MM patients

\begin{tabular}{ll}
\hline Parameters & MM patients $(\mathrm{N}=105)$ \\
\hline Age (years) & $59.8 \pm 9.1$ \\
Gender (n/\%) & $65(61.9)$ \\
Male & $40(38.1)$ \\
Female & \\
Immunoglobulin subtype (n/\%) & $59(56.1)$ \\
IgG & $24(22.9)$ \\
IgA & $19(18.1)$ \\
Bence-Jones protein & $2(1.9)$ \\
IgD & $1(1.0)$ \\
IgM & $10.0 \pm 2.4$ \\
Hb (g/dL) & $10.0 \pm 1.8$ \\
Calcium (mg/dL) & $1.6 \pm 0.5$ \\
Scr (mg/dL) & $3.9 \pm 0.7$ \\
ALB (mg/dL) & $4.8(2.8-8.4)$ \\
B2-MG (mg/L) & $191.7(169.0-228.3)$ \\
LDH (U/L) &
\end{tabular}

Data were presented as mean value \pm standard deviation, count (percentage) or median (25th-75th quantiles)

MM multiple myeloma, $l g$ immunoglobulin, $\mathrm{Hb}$ hemoglobin, $\mathrm{Scr}$ serum creatinine, $A L B$ albumin, $\beta 2-M G$ Beta-2-microglobulin, $L D H$ lactate dehydrogenase, ISS International Staging System and $41.7 \%$ respectively and the cut-off value of CircAMARCA5 relative expression was 2.242 (Fig. 1b).

\section{Association between Circ-SMARCA5 relative expression and patients' baseline characteristics}

All patients were divided into high expression and low expression groups depending on whether their CircSMARCA5 relative expression was greater than the median value in MM patients or not, which showed that Circ-SMARCA5 high expression was correlated with lower $\beta 2$-MG level $(P=0.001)$ as well as less advanced ISS stage $(P<0.001)$ (Table 2$)$.

Correlation between treatment response of $\mathrm{MM}$ patients and Circ-SMARCA5 expression.

There were 25 patients who achieved CR and 80 patients who did not. The expression of Circ-SMARCA5 was higher in $\mathrm{CR}$ patients compared to non-CR patients $(P=0.045)$ (Fig. 1c). As for ORR, 80 patients achieved ORR but 25 patients did not, and Circ-SMARCA5 expression was similar between ORR patients and nonORR patients $(P=0.458)$ (Fig. $1 \mathrm{~d})$.

\section{Factors influencing CR in MM patients}

Univariate logistic regression revealed that CircSMARCA5 (high vs low) $(\mathrm{OR}=2.597, P=0.049)$ was correlated with higher $\mathrm{CR}$, whereas $\beta 2-\mathrm{MG}(\geq 5.5 \mathrm{mg} / \mathrm{L}$ vs $<5.5 \mathrm{mg} / \mathrm{L})(\mathrm{OR}=0.332, P=0.034)$ and ISS stage (III vs $\mathrm{I} \& \mathrm{II})(\mathrm{OR}=0.332, P=0.034)$ were associated with lower CR (Table 3). Further multivariate logistic regression with Forward stepwise (Conditional) method illustrated that ISS stage (III vs I\&II) independently predicted lower $\mathrm{CR}(\mathrm{OR}=0.332, P=0.034)$ in $\mathrm{MM}$ patients.

Comparison of survivals between Circ-SMARCA5 high expression and low expression groups.

Accumulating PFS was higher in Circ-SMARCA5 high expression group compared with Circ-SMARCA5 low expression group $(P=0.004)$ (Fig. 1e). Also, accumulating OS was longer in Circ-SMARCA5 high expression group compared with Circ-SMARCA5 low expression group $(P=0.001)$ (Fig. 1f).

\section{Factors influencing PFS in MM patients}

Univariate Cox's regression disclosed that CircSMARCA5 (high vs low) $(\mathrm{HR}=0.474, P=0.006)$ was correlated with better PFS, while Scr $(\geq 2 \mathrm{mg} / \mathrm{dL}$ vs $<2$ $\mathrm{mg} / \mathrm{dL})(\mathrm{HR}=2.261, P=0.005), \beta 2-\mathrm{MG}(\geq 5.5 \mathrm{mg} / \mathrm{L}$ vs $<$ $5.5 \mathrm{mg} / \mathrm{L})(\mathrm{HR}=22.970, P<0.001)$ and ISS stage (III vs I\&II) $\quad(\mathrm{HR}=22.970, \quad P<0.001)$ were associated with worse PFS (Table 4). Additionally, multivariate Cox's regression with Forward Stepwise (Conditional) method illustrated that Durie-Salmon stage (III vs I\&II) (HR = $2.350, P=0.002)$ and ISS stage (III vs I\&II) $(\mathrm{HR}=32.620$, 
A

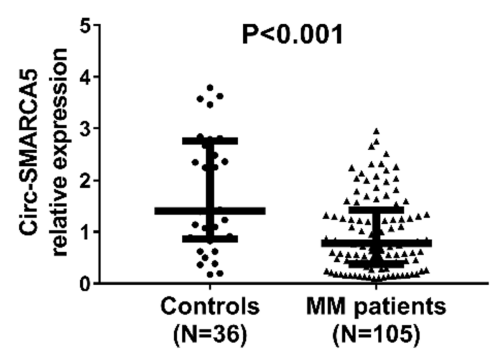

C

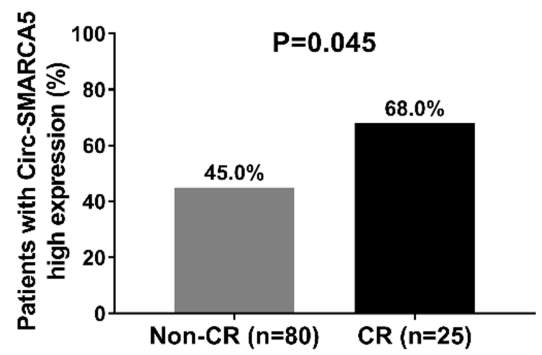

E

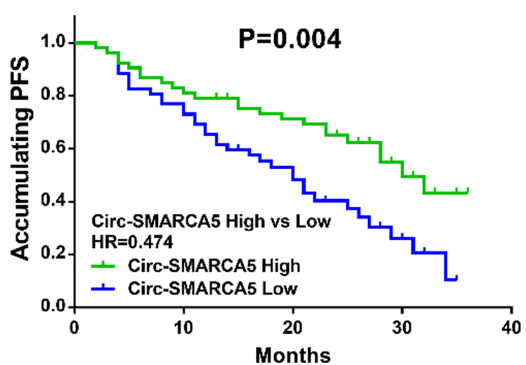

B

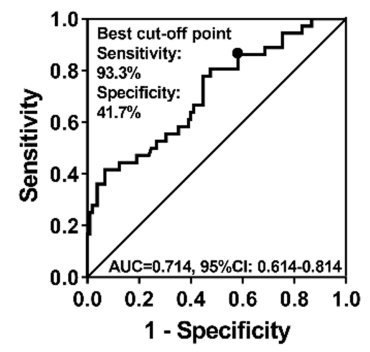

D

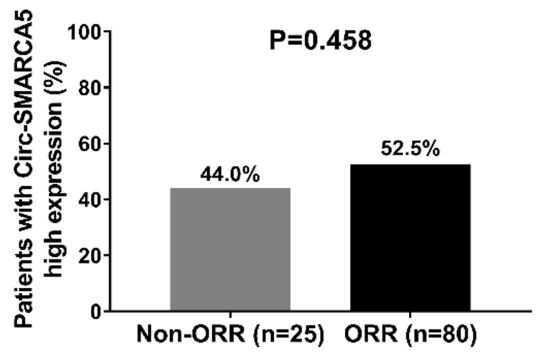

$\mathrm{F}$

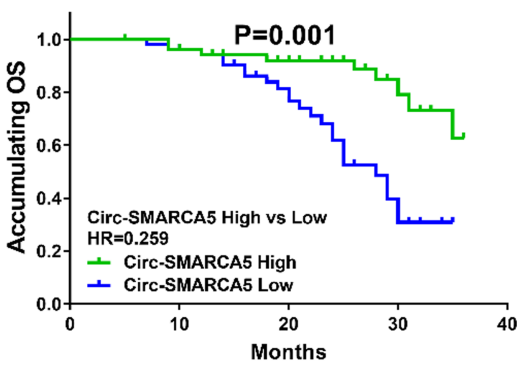

Fig. 1 a-b: Circ-SMARCA5 relative expression in MM patients. Wilcoxon rank sum test was used to compare Circ-SMARCA5 relative expression between MM patients and controls, and the ROC curve was used to evaluate the ability of Circ-SMARCA5 relative expression to discriminate between MM patients and controls. c- $\mathbf{d}$ : Association of Circ-SMARCA5 expression with treatment response in MM patients. The cutoff value of Circ-SMARCA5 was the median value of Circ-SMARCA5 in MM patients. Comparison between two groups was performed using the Chi-square test. e- $\mathbf{f}$ : Comparison of PFS and OS between Circ-SMARCA5 high expression and low expression groups. The cutoff value of Circ-SMARCA5 was the median value of Circ-SMARCA5 in MM patients. Survival curves were made using the Kaplan-Meier method and differences between the curves were determined by log-rank test. $P<0.05$ was considered significant. PFS, progression free survival; OS, overall survival; Circ-SMARCA5, Circular RNA SWI/SNF-related matrix-associated actin-dependent regulator of chromatin subfamily A member 5; ROC, Receiver operating characteristic. CR, complete response; ORR, objective response rate

$P<0.001)$ independently predicted worse PFS in MM patients.

\section{Factors influencing OS in MM patients}

Univariate Cox's regression revealed that CircSMARCA5 (high vs low) $(\mathrm{HR}=0.259, P=0.001)$ was correlated with better OS, whereas $\beta 2-\mathrm{MG}(\geq 5.5 \mathrm{mg} / \mathrm{L}$ vs $<5.5 \mathrm{mg} / \mathrm{L})(\mathrm{HR}=108.139, P<0.001)$ and ISS stage (III vs $\mathrm{I} \& \mathrm{II}))(\mathrm{HR}=108.139, P<0.001)$ were risk factors for shorter OS (Table 5). Multivariate Cox's regression with Forward Stepwise (Conditional) method was further performed, which exhibited that Circ-SMARCA5 (high vs low $)(\mathrm{HR}=0.345, \quad P=0.038) \quad$ independently predicted longer OS, while Durie-Salmon stage (III vs I\&II) (HR = 2.586, $P=0.015)$ and ISS stage (III vs I\&II) $(\mathrm{HR}=$ 148.290, $P<0.001)$ independently predicted shorter OS in $\mathrm{MM}$ patients.

\section{Circ-SMARCA5 relative expression in MM cell lines and normal plasma cells}

In order to get a deeper understanding of the underlying mechanism of Circ-SMARCA5 in MM, in vitro experiments were performed to investigate the effect of CircSMARCA5 on cell activities as well as its possible target 
Table 2 Correlation of Circ-SMARCA5 relative expression with patients' characteristics

\begin{tabular}{|c|c|c|c|}
\hline \multirow[t]{2}{*}{ Characteristics } & \multicolumn{2}{|c|}{ Circ-SMARCA5 relative expression } & \multirow[t]{2}{*}{$p$ value } \\
\hline & High & Low & \\
\hline
\end{tabular}

Age (n/\%)

$<60$ years

$23(43.4)$

$\geq 60$ years

$30(57.7)$

22 (42.3)

Gender (n/\%)

$\begin{array}{lll}\text { Male } & 34(52.3) & 31(47.7) \\ \text { Female } & 19(47.5) & 21(52.5)\end{array}$

Immunoglobulin subtypes (n/\%)

$\begin{array}{lll}\lg A & 14(58.3) & 10(41.7) \\ \lg G & 31(52.5) & 28(47.5) \\ \lg D & 1(50.0) & 1(50.0) \\ \text { Bence-Jones protein } & 7(36.8) & 12(63.2) \\ \lg M & 0(0.0) & 1(100.0)\end{array}$

$\mathrm{Hb}(\mathrm{n} / \%)$

$<10 \mathrm{~g} / \mathrm{dL}$

28 (53.8)

$\geq 10 \mathrm{~g} / \mathrm{dL}$

25 (47.12)

Calcium (n/\%)

$<11.5 \mathrm{mg} / \mathrm{dL}$

41 (53.2)

$12(42.9)$

$\geq 11.5 \mathrm{mg} / \mathrm{dL}$

$\operatorname{Scr}(n / \%)$

$<2 \mathrm{mg} / \mathrm{dL}$

$42(51.9)$

$11(45.8)$

ALB (n/\%)

$<3.5 \mathrm{mg} / \mathrm{dL}$

16 (48.5)

$\geq 3.5 \mathrm{mg} / \mathrm{dL}$

37 (51.4)

$\beta 2-M G(n / \%)$

$<5.5 \mathrm{mg} / \mathrm{L}$

$39(65.0)$

$\geq 5.5 \mathrm{mg} / \mathrm{L}$

$14(31.3)$

LDH (n/\%)

$<220 \mathrm{U} / \mathrm{L}$

39 (53.4)

$\geq 220 \mathrm{U} / \mathrm{L}$

14 (43.8)

Durie-Salmon stage (n/\%)

II

III

$3(75.0)$

$22(44.9)$

28 (53.8)

ISS stage (n/\%)

$\begin{array}{lll}\text { | } & 18(75.0) & 6(25.0) \\ \text { || } & 21(58.3) & 15(41.7) \\ \text { II } & 14(31.1) & 31(68.9)\end{array}$

Bone lesion (n/\%)

$\begin{array}{lll}\text { Yes } & 41(54.7) & 34(45.3) \\ \text { No } & 12(40.0) & 18(60.0)\end{array}$

Cytogenetics abnormalities (n/\%)

0.001

21 (35.0)

31 (68.9)

34 (46.6)

18 (56.3)

$1(25.0)$

27 (55.1)

24 (46.2)
30 (56.6)

Table 2 Correlation of Circ-SMARCA5 relative expression with patients' characteristics (Continued)

\begin{tabular}{llll}
\hline Characteristics & \multicolumn{2}{l}{ Circ-SMARCA5 relative expression } & p value \\
\cline { 2 - 3 } & High & Low & 0.056 \\
\cline { 1 - 2 } $\begin{array}{l}\text { t }(14 ; 16) \text { translocation } \\
\text { Yes }\end{array}$ & $11(73.3)$ & $4(26.7)$ & \\
No & $42(46.7)$ & $48(53.3)$ & 0.486 \\
$\mathrm{t}(4 ; 14)$ translocation & & & \\
Yes & $4(40.0)$ & $6(60.0)$ & 0.235 \\
No & $49(51.6)$ & $46(48.4)$ & \\
Del (17p) & & & \\
Yes & $5(35.7)$ & $9(64.3)$ & \\
No & $48(52.7)$ & $43(47.3)$ & \\
\hline
\end{tabular}

Data were presented as count (percentage). Patients' circ-SMARCA5 relative expression classified as high if greater than the median, and low if less than the median value. Comparison was determined by Chi-square test or Wilcoxon rank sum test. $p$ value $<0.05$ was considered significant (in bold) Ig immunoglobulin, $H b$ hemoglobin, $S c r$ serum creatinine, $A L B$ albumin, $\beta 2-M G$ Beta-2-microglobulin, LDH lactate dehydrogenase, ISS International

Staging System

in MM cells. Circ-SMARCA5 relative expression in MM cell lines and normal plasma cells was detected by qPCR, which revealed that Circ-SMARCA5 was downregulated in $\mathrm{MM}$ cell lines including NCI-H929 $(P<0.05)$, RPMI8226 $(P<0.01)$, U226 $(P<0.05)$, OPM2 $(P<0.05)$ and JJN3 $(P<0.01)$ compared to normal plasma cells (Fig. 2). The lowest expression of Circ-SMARCA5 was presented in RPMI8226 cells, thus, RPMI8226 cells were chosen to be applied in the following experiments.

\section{Circ-SMARCA5 relative expression after transfection}

To verify the transfection effects of plasmids, we used qPCR to detect the expression of Circ-SMARCA5 in RPMI8226 cells at $24 \mathrm{~h}$ after transfection, and the data showed that Circ-SMARCA5 was upregulated in SMARCA5 $(+)$ group compared to Control $(+)$ group $(P<0.001)$ but downregulated in SMARCA5 $(-)$ group compared with Control $(-)$ group $(P<0.001)$, which indicated successful transfection (Fig. 3a).

\section{Effect of Circ-SMARCA5 on cell proliferation and apoptosis}

Cell proliferation ability was reduced in SMARCA5 $(+)$ $<0.001$ group compared with Control $(+)$ group $(P<0.01)$ but promoted in SMARCA5 $(-)$ group compared with Control $(-)$ group $(P<0.01)$ at $72 \mathrm{~h}$ after transfection (Fig. $3 b)$. As for cell apoptosis rate, it was increased in SMARCA5 $(+)$ group compared with Control $(+)$ group $(P<0.01)$ but decreased in SMARCA5 $(-)$ group compared with Control $(-)$ group $(P<0.01)$ at $72 \mathrm{~h}$ after transfection (Fig. 3c, g). Western blot assay visualized that cells apoptotic marker cleaved caspase 3 was elevated in SMARCA5 $(+)$ group compared with Control 
Table 3 Factors affecting CR by logistic regression analysis

\begin{tabular}{|c|c|c|c|c|}
\hline \multirow[t]{3}{*}{ Factors } & \multicolumn{4}{|c|}{ Logistic regression model } \\
\hline & \multirow[t]{2}{*}{ p value } & \multirow[t]{2}{*}{ OR } & \multicolumn{2}{|c|}{$95 \% \mathrm{Cl}$} \\
\hline & & & Lower & Higher \\
\hline \multicolumn{5}{|l|}{ Univariate logistic regression } \\
\hline Circ-SMARCA5 (high vs low) & 0.049 & 2.597 & 1.006 & 6.707 \\
\hline Age ( $\geq 60$ years vs $<60$ years) & 0.278 & 0.603 & 0.242 & 1.502 \\
\hline Gender (male vs female) & 0.822 & 0.900 & 0.359 & 2.257 \\
\hline \multicolumn{5}{|l|}{ Immunoglobulin subtype } \\
\hline IgG vs others & 0.369 & 1.530 & 0.605 & 3.867 \\
\hline $\lg A$ vs others & 0.150 & 0.383 & 0.104 & 1.413 \\
\hline IgM vs others & 1.000 & 0.000 & 0.000 & - \\
\hline $\lg D$ vs others & 0.406 & 3.292 & 0.198 & 54.631 \\
\hline Bence-Jones protein vs others & 0.777 & 1.179 & 0.378 & 3.674 \\
\hline $\mathrm{Hb}(\geq 10 \mathrm{~g} / \mathrm{dL}$ vs $<10 \mathrm{~g} / \mathrm{dL})$ & 0.101 & 0.460 & 0.182 & 1.164 \\
\hline $\begin{array}{l}\text { Calcium } \geq 11.5 \mathrm{mg} / \mathrm{dL} \text { vs }<11.5 \mathrm{mg} / \\
\mathrm{dL} \text { ) }\end{array}$ & 0.391 & 0.620 & 0.208 & 1.848 \\
\hline $\operatorname{Scr}(\geq 2 \mathrm{mg} / \mathrm{dL}$ vs $<2 \mathrm{mg} / \mathrm{dL})$ & 0.484 & 1.441 & 0.517 & 4.014 \\
\hline ALB $(\geq 3.5 \mathrm{mg} / \mathrm{dL}$ vs $<3.5 \mathrm{mg} / \mathrm{dL})$ & 0.362 & 1.613 & 0.577 & 4.511 \\
\hline$\beta 2-M G(\geq 5.5 \mathrm{mg} / \mathrm{L}$ vs $<5.5 \mathrm{mg} / \mathrm{L})$ & 0.034 & 0.332 & 0.120 & 0.918 \\
\hline $\mathrm{LDH}(\geq 220 \mathrm{U} / \mathrm{L}$ vs $<220 \mathrm{U} / \mathrm{L})$ & 0.198 & 0.491 & 0.166 & 1.451 \\
\hline Durie-Salmon stage (III vs I\&II) & 0.233 & 1.743 & 0.700 & 4.343 \\
\hline ISS stage (III vs I\&II) & 0.034 & 0.332 & 0.120 & 0.918 \\
\hline Bone lesion (yes vs no) & 0.942 & 1.038 & 0.382 & 2.816 \\
\hline \multicolumn{5}{|l|}{ Cytogenetics abnormality } \\
\hline t $(4 ; 14)$ translocation (yes vs no) & 0.767 & 0.783 & 0.155 & 3.951 \\
\hline t $(14 ; 16)$ translocation (yes vs no) & 0.709 & 0.773 & 0.200 & 2.991 \\
\hline Del (17p) (yes vs no) & 0.377 & 0.493 & 0.103 & 2.368 \\
\hline
\end{tabular}

Multivariate logistic regression with Forward Stepwise (Conditional) method

ISS stage (III vs I\&II)

$\mathbf{0 . 0 3 4} \quad 0.332 \quad 0.120 \quad 0.918$

Factors affecting $C R$ were determined by univariate and multivariate logistic regression analyses, and the multivariate logistic regression analysis was performed with Forward Stepwise (Conditional) method. $p$ value $<0.05$ was considered significant (in bold)

$C R$ complete remission, $O R$ odds ratio, $C l$ confidence interval, $I g$ immunoglobulin, $H b$ hemoglobin, $\mathrm{Scr}$ serum creatinine, $A L B$ albumin, $\beta 2-M G$ Beta-2-microglobulin, LDH lactate dehydrogenase, ISS International Staging System

(+) group but reduced in SMARCA5 (-) group compared with Control (-) group, whereas Bcl-2 was decreased in SMARCA5 $(+)$ group compared with Control (+) group but increased in SMARCA5 (-) group compared with Control (-) group (Fig. 3d, e, f). To validate this, the above experiments were repeated in NCI-H929 cells, and similar results were observed (Fig. 4).

\section{Effect of Circ-SMARCA5 on regulating miR-561, miR-616 and miR-767-5p}

Potential target miRNAs of Circ-SMARCA5 in MM were predicted using Circular RNA Interactome database and miRanda database, and miR-561, miR-616 as well as miR-767-5p were selected for validation. The qPCR was performed to measure their expressions at 24 $\mathrm{h}$ post transfection in Control (+), SMARCA5 (+), Control (-) and SMARCA5 (-) groups, which observed that miR-561 expression was reduced in SMARCA5 (+) group compared with Control $(+)$ group $(P<0.01)$ but similar between SMARCA5 (-) group and Control (-) group $(P>0.05)$ (Fig. 5a). There was no difference in miR-616 expression between SMARCA5 (+) group and Control $(+)$ group $(P>0.05)$ or between SMARCA5 $(-)$ group and Control $(-)$ group $(P>0.05)$ (Fig. 5b). As for miR-767-5p, its expression was decreased in SMARCA5 $(+)$ group compared with Control $(+)$ group $(P<0.01)$ and increased in SMARCA5 (-) group compared with Control (-) group $(P<0.001)$ (Fig. 5c). Besides, we further validated the regulation of miR-767-5p by circSMARCA5 in NCI-H929, U226, OPM2 and JJN3 cells, which observed that circ-SMARCA5 negatively regulated miR-767-5p in NCI-H929, U226 and OPM2 significantly (all $P<0.01$ ) (Additional file 3: Figure S1A-C), while slightly regulated miR-767-5p in JJN3 cells (all $P<0.05$ ) (Additional file 3: Figure S1D).

\section{Interaction between Circ-SMARCA5 and miR-767-5p in the rescue experiment}

The interaction between Circ-SMARCA5 and miR-767$5 p$ in RPMI8226 cells was further evaluated by the rescue experiment. We observed that miR-767-5p expression was raised in miR-767 (+) group compared with Control $(+)$ group $(P<0.001)$ and also increased in SMARCA5 $(+) / \operatorname{miR}-767 \quad(+)$ group compared with SMARCA5 $(+)$ group $(P<0.001)$ (Fig. 6a). Regarding Circ-SMARCA5, no difference of its expression was observed between miR-767 (+) group and Control (+) group, or between SMARCA5 $(+) / \operatorname{miR}-767(+)$ group and SMARCA5 $(+)$ group (All $P>0.05$ ) (Fig. 6b). Therefore, Circ-SMARCA5 adversely regulated miR-767-5p expression while miR-767-5p had no effect on CircSMARCA5 expression in RPMI8226 cells.

\section{Effects of Circ-SMARCA5 and miR-767-5p on cell} proliferation and apoptosis in the rescue experiment At $72 \mathrm{~h}$ after transfection, cell proliferation ability was higher in miR-767 (+) group compared with Control (+) group $(P<0.01)$, and higher in SMARCA5 $(+) / \mathrm{miR}-767$ $(+)$ group compared with SMARCA5 $(+)$ group $(P<$ 0.01) (Fig. 7a). Cell apoptosis rate was decreased in miR$767(+)$ group compared with Control $(+)$ group $(P<$ $0.01)$, as well as in SMARCA5 $(+) / \mathrm{miR}-767(+)$ group compared with SMARCA5 $(+)$ group $(P<0.01)$ (Fig. $7 \mathrm{~b}$, f). Western blot assay exhibited that cell apoptotic marker cleaved Caspase 3 expression was reduced in miR-767 (+) group compared with Control (+) group, as 
Table 4 Factors affecting PFS by Cox's proportional hazards regression analysis

\begin{tabular}{|c|c|c|c|c|}
\hline \multirow[t]{3}{*}{ Items } & \multicolumn{4}{|c|}{ Cox's regression model } \\
\hline & \multirow[t]{2}{*}{$p$ value } & \multirow[t]{2}{*}{$\mathrm{HR}$} & \multicolumn{2}{|l|}{$95 \% \mathrm{Cl}$} \\
\hline & & & Lower & Higher \\
\hline \multicolumn{5}{|l|}{ Univariate Cox's regression } \\
\hline Circ-SMARCA5 (high vs low) & 0.006 & 0.474 & 0.278 & 0.806 \\
\hline Age ( $\geq 60$ years vs $<60$ years) & 0.390 & 1.255 & 0.748 & 2.106 \\
\hline Gender (male vs female) & 0.122 & 0.663 & 0.393 & 1.116 \\
\hline \multicolumn{5}{|l|}{ Immunoglobulin subtype } \\
\hline IgG vs others & 0.583 & 0.865 & 0.516 & 1.450 \\
\hline IgA vs others & 0.423 & 1.272 & 0.706 & 2.290 \\
\hline IgM vs others & 0.720 & 1.436 & 0.198 & 10.423 \\
\hline IgD vs others & 0.873 & 0.851 & 0.117 & 6.178 \\
\hline Bence-Jones protein vs others & 0.847 & 0.935 & 0.472 & 1.850 \\
\hline $\mathrm{Hb}(\geq 10 \mathrm{~g} / \mathrm{dL} \mathrm{vs}<10 \mathrm{~g} / \mathrm{dL})$ & 0.908 & 0.970 & 0.578 & 1.626 \\
\hline Calcium $\geq 11.5 \mathrm{mg} / \mathrm{dL}$ vs $<11.5 \mathrm{mg} / \mathrm{dL}$ ) & 0.749 & 0.906 & 0.497 & 1.655 \\
\hline $\operatorname{Scr}(\geq 2 \mathrm{mg} / \mathrm{dL}$ vs $<2 \mathrm{mg} / \mathrm{dL})$ & 0.005 & 2.261 & 1.282 & 3.990 \\
\hline ALB ( $\geq 3.5 \mathrm{mg} / \mathrm{dL}$ vs $<3.5 \mathrm{mg} / \mathrm{dL})$ & 0.792 & 1.080 & 0.612 & 1.905 \\
\hline$\beta 2-M G(\geq 5.5 \mathrm{mg} / \mathrm{L}$ vs < $5.5 \mathrm{mg} / \mathrm{L})$ & $<0.001$ & 22.970 & 9.519 & 55.426 \\
\hline $\mathrm{LDH}(\geq 220 \mathrm{U} / \mathrm{L}$ vs < $220 \mathrm{U} / \mathrm{L})$ & 0.480 & 1.219 & 0.703 & 2.113 \\
\hline Durie-Salmon stage (III vs I\&II) & 0.320 & 1.302 & 0.774 & 2.191 \\
\hline ISS stage (III vs I\&II) & $<0.001$ & 22.970 & 9.519 & 55.426 \\
\hline Bone lesion (yes vs no) & 0.239 & 0.705 & 0.393 & 1.262 \\
\hline \multicolumn{5}{|l|}{ Cytogenetics abnormality } \\
\hline t $(4 ; 14)$ translocation (yes vs no) & 0.947 & 0.972 & 0.413 & 2.286 \\
\hline t $(14 ; 16)$ translocation (yes vs no) & 0.589 & 0.804 & 0.365 & 1.773 \\
\hline Del (17p) (yes vs no) & 0.453 & 1.313 & 0.644 & 2.676 \\
\hline \multicolumn{5}{|c|}{ Multivariate Cox's regression with Forward Stepwise (Conditional) method } \\
\hline Durie-Salmon stage (III vs I\&\|) & 0.002 & 2.350 & 1.363 & 4.053 \\
\hline ISS stage (III vs I\&II) & $<0.001$ & 32.620 & 12.739 & 83.528 \\
\hline
\end{tabular}

Factors affecting PFS were determined by univariate and multivariate Cox's proportional hazards regression analyses, and the multivariate Cox's proportional hazards regression analysis was performed with Forward Stepwise (Conditional) method. $\mathrm{p}$ value $<0.05$ was considered significant (in bold)

PFS progression free survival, HR hazard ratio, $C l$ confidence interval, $l g$ immunoglobulin, $H b$ hemoglobin, $S c r$ serum creatinine, $A L B$ albumin, $\beta 2-M G$ Beta-2microglobulin, $L D H$ lactate dehydrogenase, ISS International Staging System

well as in SMARCA5 $(+) /$ miR-767 (+) group compared with SMARCA5 $(+)$ group, while Bcl-2 expression was enhanced in miR-767 $(+)$ group compared with Control $(+)$ group, and in SMARCA5 $(+) /$ miR-767 (+) group compared with SMARCA5 $(+)$ group (Fig. 7c, d, e). These results indicated that Circ-SMARCA5 suppressed cell proliferation and promoted cell apoptosis via targeting miR-767-5p in RPMI8226 cells.

\section{Relative luciferase activity of Circ-SMARCA5}

In order to further validate the targeting effect of CircSMARCA5 on miR-767-5p, luciferase reporter assay was subsequently conducted to confirm the binding site of Circ-SMARCA5 with miR-767-5p. The sequences of Circ-SMARCA5 wild/mutant type and miR-767-5p were shown and the binding sites were marked in Fig. 8a. For wild type Circ-SMARCA5, the relative luciferase activity was lower in miR-767-5p group compared to miR-NC group $(P<0.01)$, whereas for mutant Circ-SMARCA5, there was no difference in relative luciferase activity between miR-767-5p group and miR-NC group $(P>0.05)$ (Fig. 8b). This validated that Circ- SMARCA5 interacted with miR-767-5p by direct binding in RPMI8226 cells.

\section{Discussion}

Our study discovered that: (1) Circ-SMARCA5 expression was downregulated in MM patients, and its high expression was correlated with lower $\beta 2-\mathrm{MG}$ level and ISS stage. (2) Circ-SMARCA5 expression was positively associated with treatment response and survival in MM 
Table 5 Factors affecting OS by Cox's proportional hazards regression analysis

\begin{tabular}{|c|c|c|c|c|}
\hline \multirow[t]{3}{*}{ Items } & \multicolumn{4}{|c|}{ Cox's regression model } \\
\hline & \multirow[t]{2}{*}{$p$ value } & \multirow[t]{2}{*}{$H R$} & \multicolumn{2}{|l|}{$95 \% \mathrm{Cl}$} \\
\hline & & & Lower & Higher \\
\hline \multicolumn{5}{|l|}{ Univariate Cox's regression } \\
\hline Circ-SMARCA5 (high vs low) & 0.001 & 0.259 & 0.119 & 0.565 \\
\hline Age ( $\geq 60$ years vs $<60$ years) & 0.545 & 1.238 & 0.620 & 2.472 \\
\hline Gender (male vs female) & 0.074 & 0.535 & 0.269 & 1.064 \\
\hline \multicolumn{5}{|l|}{ Immunoglobulin subtype } \\
\hline lgG vs others & 0.805 & 1.091 & 0.546 & 2.179 \\
\hline $\lg A$ vs others & 0.936 & 0.966 & 0.418 & 2.231 \\
\hline IgM vs others & 0.609 & 0.048 & 0.000 & 5345.739 \\
\hline IgD vs others & 0.837 & 1.233 & 0.168 & 9.065 \\
\hline Bence-Jones protein vs others & 0.959 & 0.977 & 0.403 & 2.369 \\
\hline $\mathrm{Hb}(\geq 10 \mathrm{~g} / \mathrm{dL}$ vs $<10 \mathrm{~g} / \mathrm{dL})$ & 0.616 & 1.193 & 0.600 & 2.371 \\
\hline Calcium $\geq 11.5 \mathrm{mg} / \mathrm{dL}$ vs $<11.5 \mathrm{mg} / \mathrm{dL}$ ) & 0.507 & 1.286 & 0.611 & 2.705 \\
\hline $\operatorname{Scr}(\geq 2 \mathrm{mg} / \mathrm{dL}$ vs $<2 \mathrm{mg} / \mathrm{dL})$ & 0.858 & 1.085 & 0.445 & 2.645 \\
\hline ALB $(\geq 3.5 \mathrm{mg} / \mathrm{dL}$ vs $<3.5 \mathrm{mg} / \mathrm{dL})$ & 0.887 & 0.947 & 0.448 & 2.001 \\
\hline$\beta 2-M G(\geq 5.5$ mg/L vs < 5.5 mg/L) & $<0.001$ & 108.139 & 14.142 & 826.884 \\
\hline $\mathrm{LDH}(\geq 220 \mathrm{U} / \mathrm{L}$ vs < $220 \mathrm{U} / \mathrm{L})$ & 0.385 & 1.370 & 0.673 & 2.789 \\
\hline Durie-Salmon stage (III vs I\&II) & 0.287 & 1.465 & 0.725 & 2.959 \\
\hline ISS stage (III vs I\&II) & $<0.001$ & 108.139 & 14.142 & 826.884 \\
\hline Bone lesion (yes vs no) & 0.687 & 0.854 & 0.395 & 1.842 \\
\hline \multicolumn{5}{|l|}{ Cytogenetics abnormality } \\
\hline t $(4 ; 14)$ translocation (yes vs no) & 0.747 & 0.822 & 0.250 & 2.706 \\
\hline t $(14 ; 16)$ translocation (yes vs no) & 0.465 & 0.642 & 0.196 & 2.106 \\
\hline Del (17p) (yes vs no) & 0.575 & 1.314 & 0.506 & 3.408 \\
\hline \multicolumn{5}{|c|}{ Multivariate Cox's regression with Forward Stepwise (Conditional) method } \\
\hline Circ-SMARCA5 (high vs low) & 0.038 & 0.345 & 0.127 & 0.941 \\
\hline Durie-Salmon stage (III vs I\&II) & 0.015 & 2.586 & 1.206 & 5.546 \\
\hline ISS stage (III vs I\&II) & $<0.001$ & 148.290 & 17.354 & 1267.115 \\
\hline
\end{tabular}

Factors affecting OS were determined by univariate and multivariate Cox's proportional hazards regression analyses, and the multivariate Cox's proportional hazards regression analysis was performed with Forward Stepwise (Conditional) method. $\mathrm{p}$ value $<0.05$ was considered significant (in bold)

OS overall survival, $H R$ hazard ratio, $C l$ confidence interval, Ig immunoglobulin, $H b$ hemoglobin, Scr serum creatinine, ALB albumin, $\beta 2-M G$ Beta-2-microglobulin,

LDH lactate dehydrogenase, ISS International Staging System

patients. (3) In vitro experiments disclosed that CircSMARCA5 reduced cell proliferation but improved cell apoptosis via sponging miR-767-5p in MM cells.

MM is currently incurable, and its clinical manifestations are not apparent until the oncological events initiate and progress for a decade in most cases, leading to late diagnosis and unfavorable treatment outcomes [2]. Conventional therapy for MM depends on chemotherapy using cytotoxic agents, while the native resistance to drugs is common due to multiple chromosomal abnormities in the pathogenesis of MM, resulting in unfavorable treatment response and survivals in MM patients [1]. Therefore, identifying biomarkers that could predict the risk as well as prognosis of MM will help with timely diagnosis and treatment for MM patients. Moreover, the detailed mechanism underling the development and progression of MM is still not fully understood, thus, studies investigating the mechanism of MM etiopathology are greatly needed.

CircRNAs are widely expressed in human cells with relatively higher expression and more stable structure compared with their linear counterparts, suggesting that CircRNAs could be the ideal biomarkers for human diseases [7]. Accumulating studies have disclosed that CircRNAs might hold missing triggers of tumorigenesis of various cancers including hematopoietic cancers by regulating gene expression [15, 19-21]. For instance, Circ-ANAPC7 is predominantly upregulated in AML by 


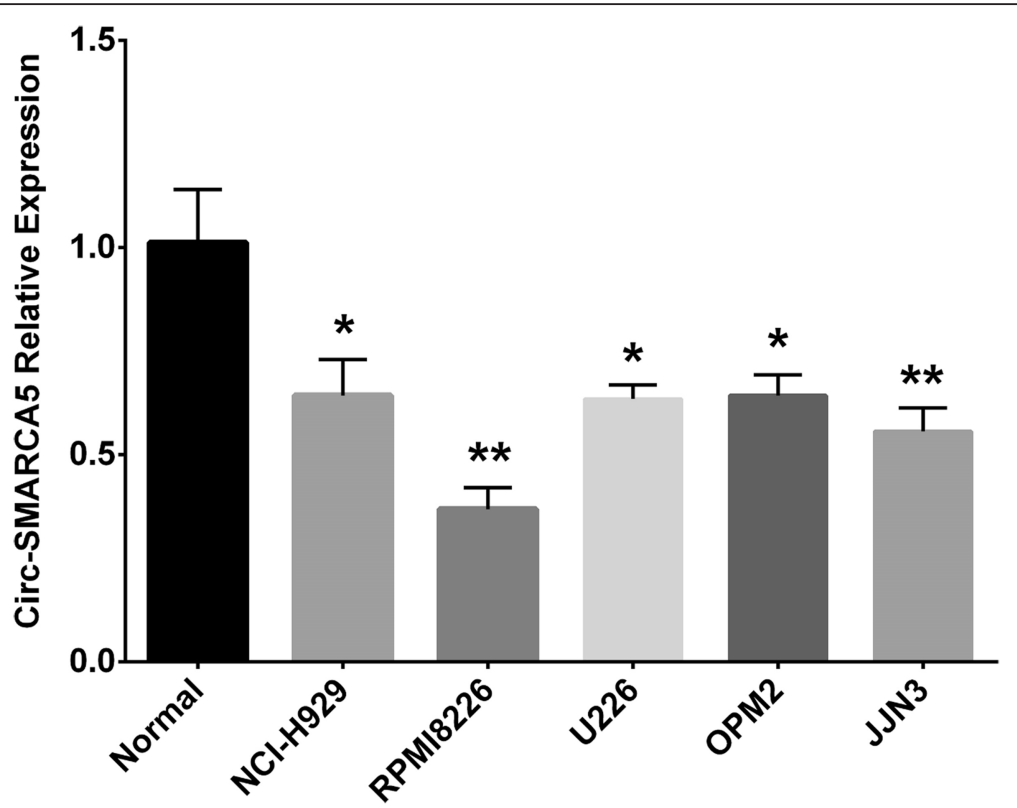

Fig. 2 Comparing Circ-SMARCA5 expression in MM cell lines and control cells. Circ-SMARCA5 expression was decreased in MM cell lines including NCl-H929, RPMI8226, U226, OPM2 and JJN3 compared with control cells, and RPMI8226 cells presented the lowest Circ-SMARCA5 expression. Comparison of Circ-SMARCA5 expression between control cells and each MM cell line was performed by $\mathrm{t}$ test, and $P<0.05$ was considered significant. ${ }^{*} P<0.05,{ }^{* *} P<0.01$. Circ-SMARCA5, Circular RNA SWI/SNF-related matrix-associated actin-dependent regulator of chromatin subfamily A member 5

CircRNA microarray analysis and might serve as a promising diagnostic marker for AML [9]. Another study illustrates that Circ_0004277 is notably downregulated in acute myeloid leukemia (AML) and its high expression predicts better treatment response to chemotherapy, acting as one of the diagnostic and treatment targets for AML [10]. In addition, Circ-CBFB has been exhibited to be overly expressed in chronic lymphocytic leukemia (CLL) and serves as a diagnostic and prognostic biomarker for CLL [8]. These previous studies suggest that some CircRNAs play important roles in hematological malignancies and potentially function as promising diagnostic and prognostic markers.

Circ-SMARCA5 is a typical CircRNA derived from exons of SMARCA gene, and very limited studies investigating its role in cancer have been carried out until now [22]. For instance, Circ-SMARCA5 is initially reported to be upregulated in prostate cancer and serves as an oncogene by promoting cancer cell proliferation and inhibiting cell apoptosis [23]. Another research reveals that Circ-SMARCA5 level is reduced in hepatocellular carcinoma (HCC) tissues compared with adjacent tissues and its low expression is correlated with poor clinicopathological features in HCC patients [14]. According to these studies, the role of Circ-SMARCA5 in development of solid tumors is controversial. Besides, it is still unknown whether Circ-SMARCA5 is involved in MM or not. In vitro studies have shown that SMARCA5 gene is dysregulated in hematopoietic progenitors that could also potentially develop into MM cells, therefore, we speculated that Circ-SMARCA5, which is encoded from SMARCA5 gene, might play critical roles in MM etiology $[15,24]$. In this study, we compared the expression of Circ-SMARCA5 in MM patients with that of controls, which revealed that Circ-SMARCA5 was downregulated in MM patients compared to controls. Moreover, we also found that Circ-SMARCA5 high expression was correlated with lower $\beta 2-$ MG level and ISS stage in MM patients. Here are several possible explanations: (1) Circ-SMARCA5 might be one of the antioncogenes whose expression was inhibited by the onset of MM, therefore, Circ-SMARCA5 expression was downregulated in MM patients. (2) Circ-SMARCA5 might participate in cell cycle regulation by inhibiting cell proliferation and promoting cell apoptosis in MM cells to attenuate disease development and progression, thereby reduced disease severity in MM patients, which was validated in our followed in vitro experiments.

Additionally, we also investigated the prognostic value of Circ-SMARCA5 in MM patients and discovered that Circ-SMARCA5 high expression was correlated with better treatment response to chemotherapy and longer survival, indicating that patients with Circ-SMARCA5 high expression were more sensitive to clinical treatment. These could be due to that: (1) Circ-SMARCA5 might function as an anti-tumor gene whose high 


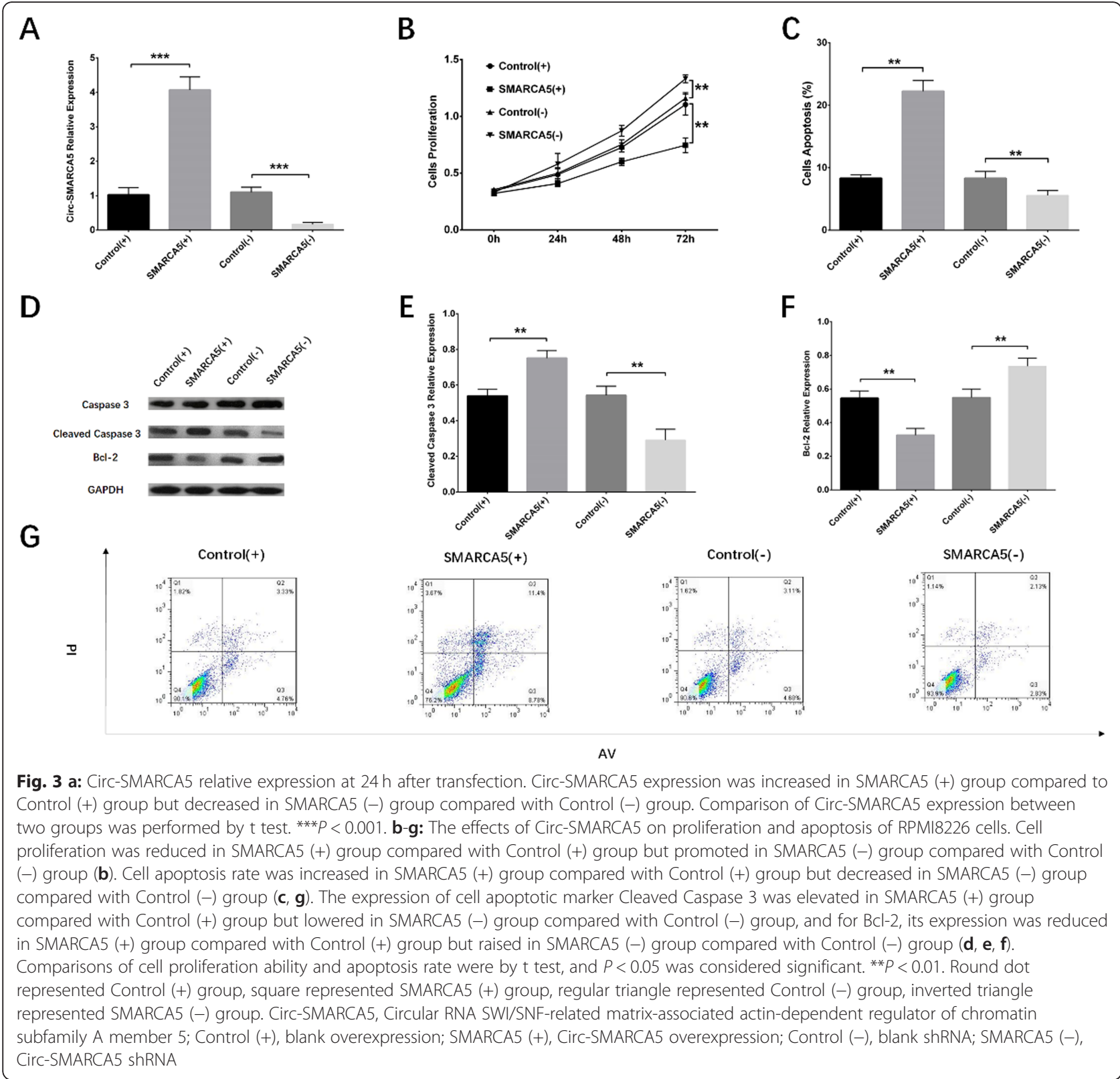

expression was associated with lower disease severity. Thus, MM patients with higher Circ-SMARCA5 presented with less advanced disease (lower ISS stage or Durie-Salmon stage), thereby leading to better treatment outcomes, which was further supported by results from Multivariate Cox's regression analysis in our study. (2) Circ-SMARCA5 might affect cells sensitivity to cytotoxic drugs, thereby resulting in better treatment response to chemotherapy and prolonging survival in MM patients. However, further validation is needed focusing on the influence of Circ-SMARCA5 on chemoresistance. Moreover, the sample size of this study was relatively small, which might influence statistical power. Also, the followup time for evaluating survivals was relatively short, therefore the effect of Circ-SMARCA5 on long-term prognosis in MM patients was still not clear in this study.

The mechanisms of CircRNAs in oncogenesis of human malignancies are still not well recognized, nonetheless, studies have discovered that CircRNAs act as miRNA sponges to negatively regulate miRNAs and protein transcription, which assist with understanding of CircRNAs in human cancers $[10,25]$. For instance, Circ_0000673 inhibits cell proliferation but promotes cell apoptosis of gastric cancer cells via adversely regulating miR-532-5p [26]. As for breast cancer (BC), Circ 0008039 functions as competing endogenous RNA and increases cell proliferation as well as cells migration via 


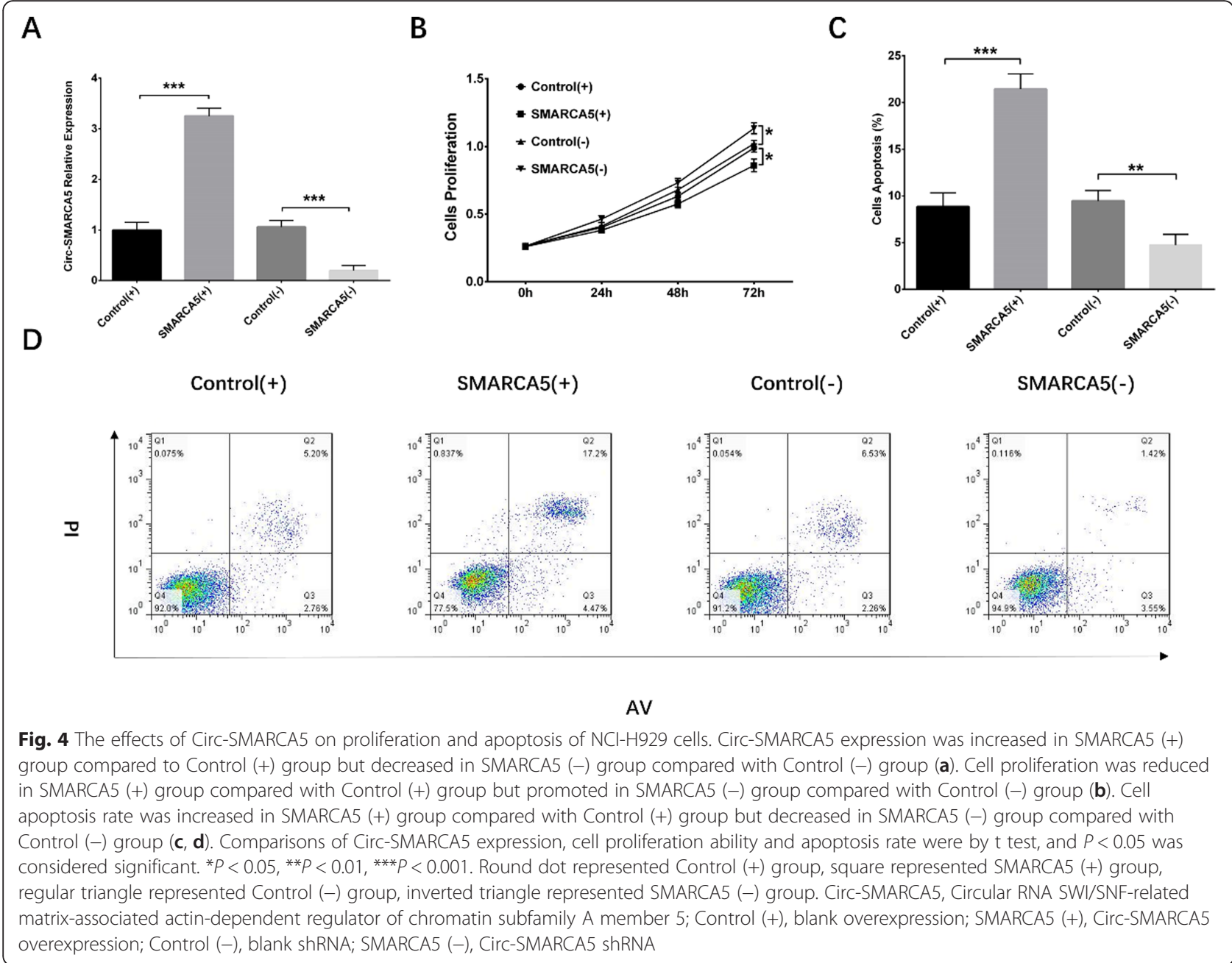

A

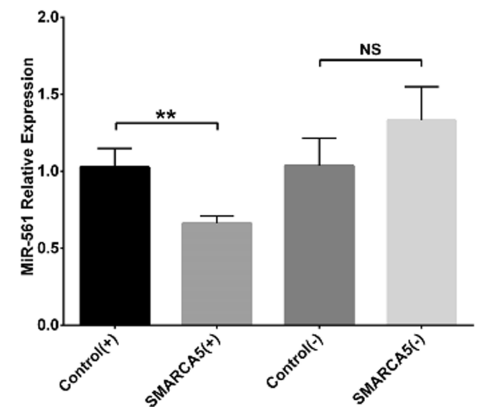

B

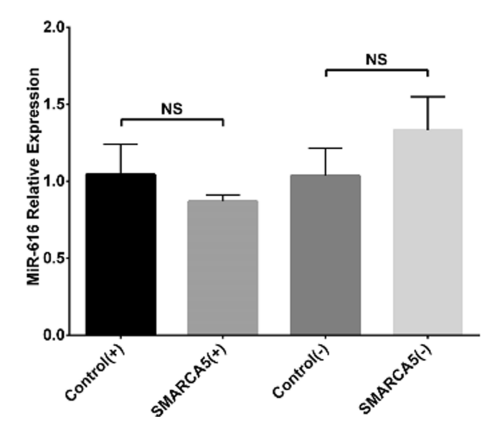

C

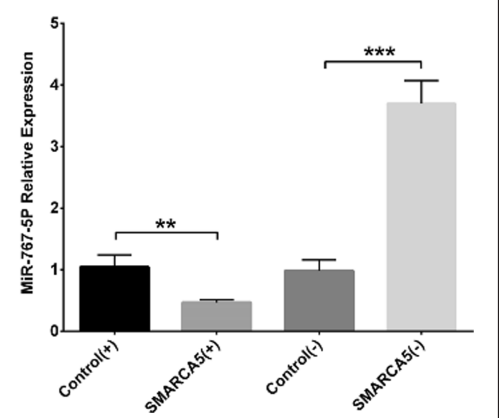

Fig. 5 Expression of miR-561, miR-616 and miR-767-5p after transfection. At $72 \mathrm{~h}$ after transfection in RPMI8226 cells, miR-561 expression was reduced in SMARCA5 (+) group compared with Control (+) group but similar in SMARCA5 (-) group compared with Control (-) group (a). No difference in expression of miR-616 was observed between SMARCA5 (+) and Control (+) groups, or between SMARCA5 (-) and Control $(-)$ groups (b). As for miR-767-5p, its expression was reduced in SMARCA5 $(+)$ group compared with NC (+) group but raised in SMARCA5 (-) group compared with Control (-) group. Comparisons of miRNA expressions were performed using $t$ test and $P<0.05$ was considered significant. ${ }^{* *} P<$ $0.01,{ }^{* * *} P<0.001$, NS, non-significant. Control (+), blank overexpression; SMARCA5 (+), Circ-SMARCA5 overexpression; Control (-), blank shRNA; SMARCA5 (-), Circ-SMARCA5 shRNA; miR, micro RNA 
A

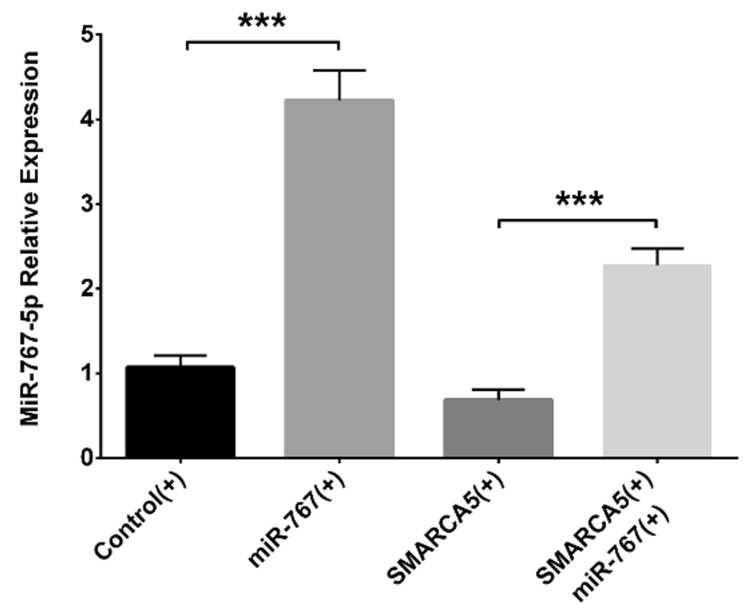

B

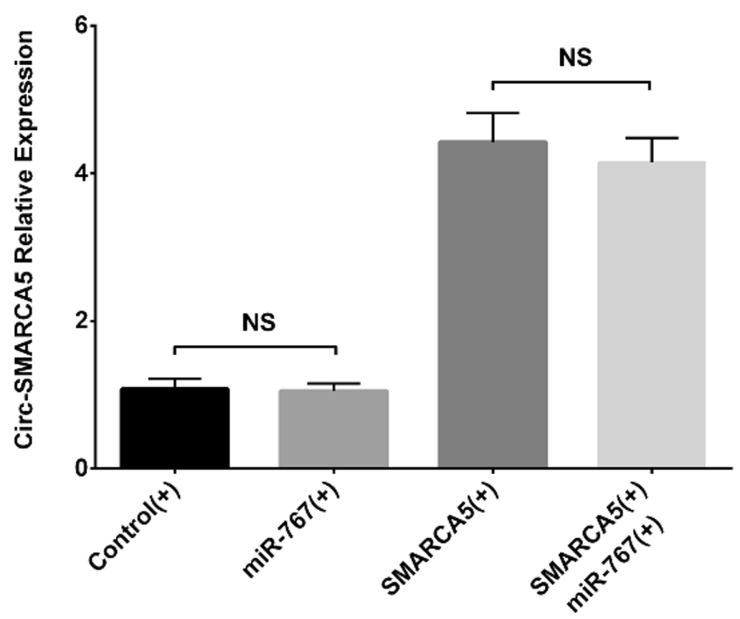

Fig. 6 Effect of Circ-SMARCA5 on miR-767-5p expression. MiR-767-5p expression was increased in miR-767 (+) group compared with Control (+) group, as well as in SMARCA5 (+)/miR-767 (+) group compared to SMARCA5 (+) group (a). No difference in Circ-SMARCA5 expression was observed between miR-767 (+) group and Control (+) group as well as between SMARCA5 (+) group and SMARCA5 (+)/miR-767 (+) group (b). Comparisons of miR-767-5p expression and Circ-SMARCA5 expression were conducted using t test and $P<0.05$ was considered significant. ${ }^{* * *} P<$ 0.001, NS, non-significant. Circ-SMARCA5, Circular RNA SWI/SNF-related matrix-associated actin-dependent regulator of chromatin subfamily A member 5; Control (+), blank overexpression; miR-767 (+), miR-767-5p overexpression; SMARCA5 (+), Circ-SMARCA5 overexpression; SMARCA5 $(+) /$ miR-767 (+), miR-767-5p overexpression \& Circ-SMARCA5 overexpression

A

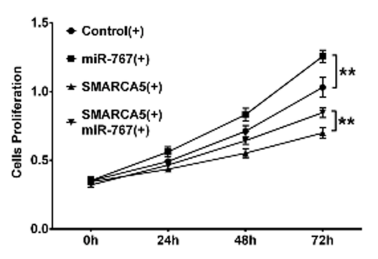

E

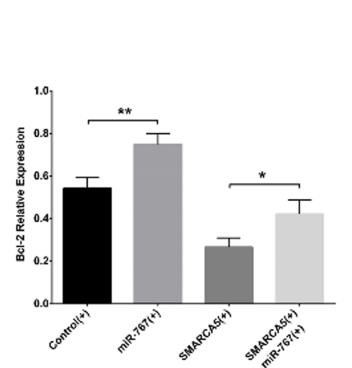

B

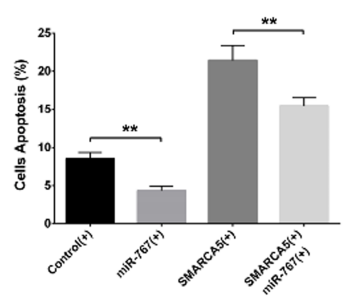

F

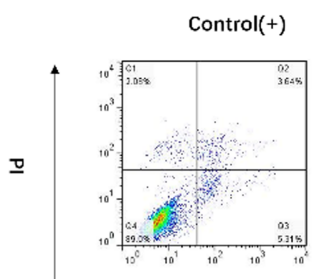

C

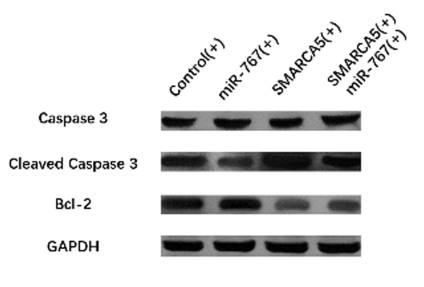

D

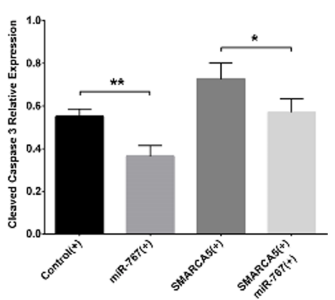

miR-767(+)

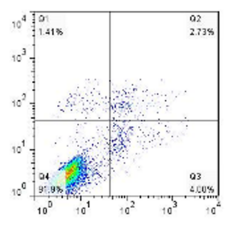

SMARCA5(+)

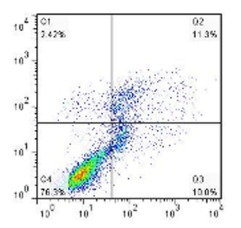

SMARCA5(+) $\operatorname{miR}-767(+)$

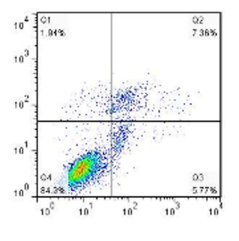

AV

Fig. 7 Effect of Circ-SMARCA5 on cell proliferation and apoptosis in the rescue experiment. Cell proliferation was promoted in miR-767 (+) group compared with Control $(+)$ group as well as in SMARCA5 (+)/miR-767 (+) group compared with SMARCA5 (+) group (a). Cell apoptosis rate was decreased in miR-767 (+) group compared with Control (+) group as well as in SMARCA5 (+)/miR-767 (+) group compared with SMARCA5 (+) group (b, d). The expression of cell apoptotic marker Cleaved Caspase 3 was reduced in miR-767 (+) group compared with Control (+) group but raised in SMARCA5 (+)/miR-767 (+) group compared with SMARCA5 (+) group, and for Bcl-2, its expression was promoted in miR-767 (+) group compared with Control (+) group as well as in SMARCA5 (+)/miR-767 (+) group compared with SMARCA5 (+) group (c). Comparisons of cell proliferation ability and apoptosis rate were by $t$ test, and $P<0.05$ was considered significant. ${ }^{* *} P<0.01$. Round dot represented Control $(+)$ group, square represented miR-767 (+) group, regular triangle represented SMARCA5 (+), inverted triangle represented SMARCA5 (+)/miR-767 (+) group. Circ-SMARCA5, Circular RNA SWI/SNF-related matrix-associated actin-dependent regulator of chromatin subfamily A member 5; miR, micro RNA; Control (+), blank overexpression; miR-767 (+), miR-767-5p overexpression; SMARCA5 (+), Circ-SMARCA5 overexpression; SMARCA5 (+)/miR767 (+), miR-767-5p overexpression \& Circ-SMARCA5 overexpression 


\section{A 5’ GATGGTCAGACACCCCATGATGAG 3’ circ-SMARCA5 Wild Type (WT) 3’ GTACGAGTCTGT-TGGTACCACGT 5’ miR-767-5p 5’ GAACGAGTCTGTCCGGTACAACAG 3’ circ-SMARCA5 Mutant (Mut)}

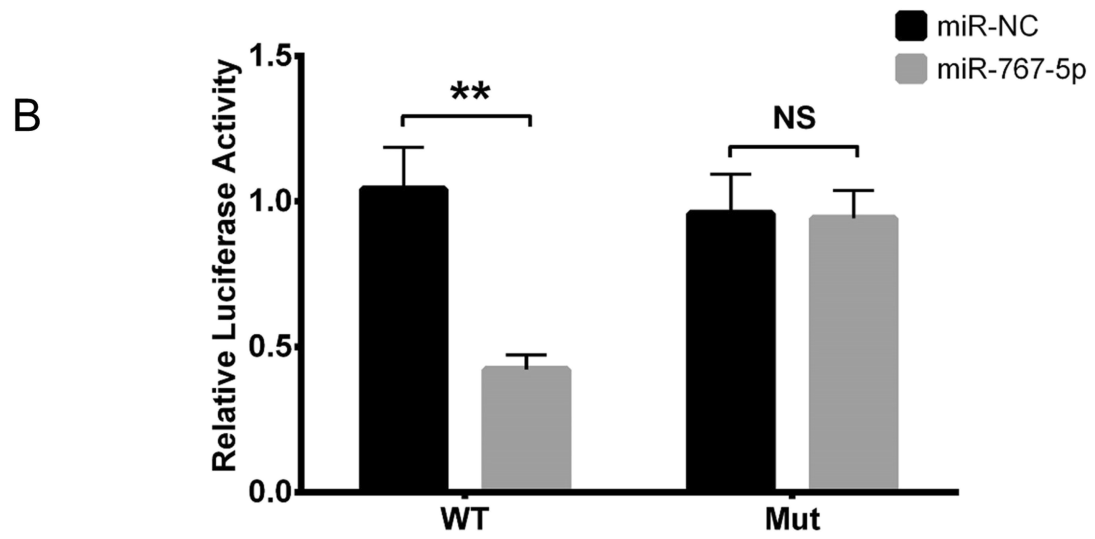

Fig. 8 Luciferase reporter assay of Circ-SMARCA5. The sequences of wild type Circ-SMARCA5, mutant type Circ-SMARCA5 and miR-767-5p were shown and the binding sites were lined up (a). For wild type Circ-SMARCA5, the relative luciferase activity was decreased in miR-767-5p group compared to miR-NC group, whereas for mutant type Circ-SMARCA5, the relative luciferase activity was similar between miR-767-5p group and miR-NC group (b). Comparison of relative luciferase activity between the two groups was conducted using t test, and $P<0.05$ was considered significant. ${ }^{*} P<0.01$, NS, non-significant. Circ-SMARCA5, Circular RNA SWI/SNF-related matrix-associated actin-dependent regulator of chromatin subfamily A member 5; miR, micro RNA

sponging miR-432-5p and altering E2F3 [27]. In hematological malignancies, Circ-CBFB is overexpressed in CLL and is a sponge of miR-607, which promotes CLL cell proliferation but suppresses cell apoptosis via activating FZD3 and the following Wnt/ $\beta$-catenin pathway [8]. Also, a bioinformatic analysis elucidates that Circ-ANAPC7, which is increasingly expressed in AML, facilitates AML pathogenesis by serving as a sponge of miR-181 family [9]. Although previous functional studies have illustrated the mechanisms of several CircRNAs in hematological malignancies, the mechanism of CircSMARCA5, a typical CricRNA, is still not clear in these cancers, nor in MM. In order to further understand how Circ-SMARCA5 acted in MM, we performed in vitro experiments and disclosed that Circ-SMARCA5 was downregulated in MM cells lines, and it inhibited proliferation but promoted apoptosis of MM cells. This suggested that Circ-SMARCA5 might work as an antioncogene and be a potential therapeutic target for MM.

MiRNAs are single-stranded non-coding RNAs with length of 19-22 nucleotides, which are common targets of CircRNAs and are involved in cells growth, proliferation, apoptosis and differentiation by incomplete base pairing with messenger RNAs (mRNAs) [28]. MiR-767-5p is a member of miR-767 that are located on chromosome X (location: NC_000023.11
$(152,393,421 . .152393529$, complement)) [22]. In human melanoma, miR-767 is shown to promote cell proliferation by suppressing cylindromatosis [29]. Another functional experiment displays that aberrant activation of miR-767 devotes to tumor epigenesis in lung cancer via repressing TET1/3 mRNA and regulating genomic 5methylcytosines to 5-hydroxymethylcytosines levels [11]. These previous studies disclose the oncogenic role of miR-767 in several human cancers, whereas in MM, the function of miR-767 still lacks investigation, and only two studies have been disclosed: the first study observed that miR-767-5p was upregulated in both tissue (two folds) and plasma samples (four folds) from MM patients compared to normal control, and it promotes MM cells (H929 and MM.1S) progression via regulating MAPK4 pathway [30]; the second study observed that miR-767-5p was overexpression in extramedullary relapse $\mathrm{MM}$ samples compared to non-extramedullary relapse MM samples [31]. In order to explore the potential target miRNA of Circ-SMARCA5 in MM, we referred to Circular RNA Interactome database (https://Circinteractome.nia.nih.gov/) and miRanda database (http://www.microrna.org/micr orna/home.do) and found that miR-767-5p might be a potential target for Circ-SMARCA5 in etiology of MM. To testify this hypothesis, we further performed rescue experiments, which illuminated that Circ-SMARCA5 suppressed 
cell proliferation but facilitated cell apoptosis by adversely regulating miR-767-5p in RPMI8226 cells. Moreover, the direct binding between Circ-SMARCA5 and miR-767-5p was illustrated by luciferase reporter assay.

\section{Conclusions}

In conclusion, Circ-SMARCA5 is downregulated and correlated with lower $\beta 2-\mathrm{MG}$ level and ISS stage as well as better prognosis in MM patients, and it inhibits proliferation but promotes apoptosis of MM cells via directly sponging miR-767-5p.

\section{Additional files}

Additional file 1: Table S1. Primers applied in qPCR. (DOCX $14 \mathrm{~kb}$ ) Additional file 2: Table S2. Antibodies applied in Western Blot. (DOCX $14 \mathrm{~kb}$ )

Additional file 3: Figure S1. Validation for the regulatory effect of Circ-SMARCA5 on miR-767-5p. Description of data: The expression of miR767-5p was decreased in SMARCA5 (+) group compared with Control(+) group and increased in SMARCA5(-) group compared with Control(-) group in NCI-H299 cells (A), U226 cells (B), OPM2 cells (C) and JJN3 cells (D). Comparisons of miR-767-5p expressions were performed using t test and $P<0.05$ was considered significant. ${ }^{*} P<0.05$, $<{ }^{* *} P<0.01$, ${ }^{* * *} P<$ 0.001. Control (+), blank overexpression; SMARCA5 (+), Circ-SMARCA5 overexpression; Control (-), blank shRNA; SMARCA5 (-), Circ-SMARCA5 shRNA; miR, micro RNA. (DOCX 320 kb)

\section{Abbreviations}

ALB: Albumin; Cl: Confidence interval; Circ-SMARCA5: Circular RNA SWI/SNFrelated matrix-associated actin-dependent regulator of chromatin subfamily A member 5; CR: Complete remission; Hb: Hemoglobin; HCC: Hepatocellular carcinoma; Ig: Immunoglobulin; ISS: International Staging System; LDH: Lactate dehydrogenase; miR: micro RNA; MM: Multiple myeloma; NS: Non-significant; OR: Odds ratio; ORR: Overall response rate; QPCR: quantitative polymerase chain reaction; ROC: Receiver operating characteristic; Scr: Serum creatinine; $\beta 2-M G$ : Beta-2-microglobulin

\section{Acknowledgments}

Not applicable.

\section{Authors' contributions}

$\mathrm{HL}, \mathrm{YW}, \mathrm{SW}$ and $\mathrm{HH}$ contributed to the conception; HL and YW contributed to the experiment. $\mathrm{HL}, \mathrm{YW}, \mathrm{J}$ and $\mathrm{CZ}$ data acquisition and data analysis; $\mathrm{HL}$, YW, YJ, XW and LH drafted the manuscript. SW, JJ, CZ and HH revised the manuscript. All authors read and approved the final manuscript.

\section{Funding}

This study was supported by the National Natural Science Foundation of China (grant no. 81201857) and the Science and Technology Project of Nantong City (grant no. MS12016012). Nantong Science and Technology Program (grant no. MS22015055). Funding from National Natural Science Foundation of China (grant no. 81201857) was used for study design and preliminary literature investigation; Technology Project of Nantong City (grant no. MS12016012) was used for laboratory and researcher expenses; Nantong Science and Technology Program (grant no. MS22015055) was used for data analysis, interpretation and manuscript writing.

\section{Availability of data and materials}

The datasets used and/or analysed during the current study are available from the corresponding author on reasonable request.

\section{Ethics approval and consent to participate}

The present study was approved by the Ethics Committee of the Affiliated Hospital of Nantong University, and all participants provided written informed consents.

\section{Consent for publication}

Not applicable.

\section{Competing interests}

The authors declare that they have no competing interests.

Received: 3 January 2019 Accepted: 26 August 2019

Published online: 10 October 2019

References

1. Zaidi AA, Vesole DH. Multiple myeloma: an old disease with new hope for the future. CA Cancer J Clin. 2001;51(5):273-85 quiz 286-279.

2. Katzel JA, Hari $P$, Vesole DH. Multiple myeloma: charging toward a bright future. CA Cancer J Clin. 2007;57(5):301-18.

3. Chim CS, Kumar SK, Orlowski RZ, Cook G, Richardson PG, Gertz MA, et al. Management of relapsed and refractory multiple myeloma: novel agents, antibodies, immunotherapies and beyond. Leukemia. 2018;32(2):252-62.

4. Anastasiadou E, Jacob LS, Slack FJ. Non-coding RNA networks in cancer. Nat Rev Cancer. 2018;18(1):5-18.

5. Zhang Z, Yang T, Xiao J. Circular RNAs: promising biomarkers for human diseases. EBioMedicine. 2018;34:267-74.

6. Lei B, Tian Z, Fan W, Ni B. Circular RNA: a novel biomarker and therapeutic target for human cancers. Int J Med Sci. 2019;16(2):292-301.

7. Li Y, Zheng Q, Bao C, Li S, Guo W, Zhao J, et al. Circular RNA is enriched and stable in exosomes: a promising biomarker for cancer diagnosis. Cell Res. 2015;25(8):981-4.

8. Xia L, Wu L, Bao J, Li Q, Chen X, Xia H, et al. Circular RNA circ-CBFB promotes proliferation and inhibits apoptosis in chronic lymphocytic leukemia through regulating miR-607/FZD3/Wnt/beta-catenin pathway. Biochem Biophys Res Commun. 2018;503(1):385-90.

9. Chen H, Liu T, Liu J, Feng Y, Wang B, Wang J, et al. Circ-ANAPC7 is upregulated in acute myeloid leukemia and appears to target the MiR-181 family. Cellular physiology and biochemistry : international journal of experimental cellular physiology, biochemistry, and pharmacology. 2018; 47(5):1998-2007.

10. Li W, Zhong C, Jiao J, Li P, Cui B, Ji C, et al. Characterization of hsa_cirC_ 0004277 as a new biomarker for acute myeloid leukemia via circular RNA profile and bioinformatics analysis. Int J Mol Sci. 2017;18(3).

11. Mani SA, Guo W, Liao MJ, Eaton EN, Ayyanan A, Zhou AY, et al. The epithelial-mesenchymal transition generates cells with properties of stem cells. Cell. 2008;133(4):704-15.

12. Tian JDC, Liang L. Involvement of circular RNA SMARCA5/microRNA-620 axis in the regulation of cervical cancer cell proliferation, invasion and migration. Eur Rev Med Pharmacol Sci. 2018;22(24):8589-98.

13. Li Z, Zhou Y, Yang G, He S, Qiu X, Zhang L, et al. Using circular RNA SMARCA5 as a potential novel biomarker for hepatocellular carcinoma. Clinica chimica acta; international journal of clinical chemistry. 2019;492:3744.

14. Yu J, Xu QG, Wang ZG, Yang Y, Zhang L, Ma JZ, et al. Circular RNA CSMARCA5 inhibits growth and metastasis in hepatocellular carcinoma. J Hepatol. 2018;68(6):1214-27.

15. Stopka T, Zakova D, Fuchs O, Kubrova O, Blafkova J, Jelinek J, et al. Chromatin remodeling gene SMARCA5 is dysregulated in primitive hematopoietic cells of acute leukemia. Leukemia. 2000;14(7):1247-52.

16. Durie BG, Salmon SE. A clinical staging system for multiple myeloma. Correlation of measured myeloma cell mass with presenting clinical features, response to treatment, and survival. Cancer. 1975;36(3):842-54.

17. Greipp PR, San Miguel J, Durie BG, Crowley JJ, Barlogie B, Blade J, et al. International staging system for multiple myeloma. Journal of clinical oncology : official journal of the American Society of Clinical Oncology. 2005;23(15):3412-20.

18. Rajkumar SV, Harousseau JL, Durie B, Anderson KC, Dimopoulos M, Kyle R, et al. Consensus recommendations for the uniform reporting of clinical trials: report of the international myeloma workshop consensus panel 1. Blood. 2011;117(18):4691-5. 
19. Bi J, Liu H, Cai Z, Dong W, Jiang N, Yang M, et al. Circ-BPTF promotes bladder cancer progression and recurrence through the miR-31-5p/RAB27A axis. Aging. 2018;10(8):1964-76.

20. Fang L, Du WW, Lyu J, Dong J, Zhang C, Yang W, et al. Enhanced breast cancer progression by mutant p53 is inhibited by the circular RNA circCcnb1. Cell Death Differ. 2018.

21. Yuan Y, Liu W, Zhang Y, Zhang Y, Sun S. CircRNA circ_0026344 as a prognostic biomarker suppresses colorectal cancer progression via microRNA-21 and microRNA-31. Biochem Biophys Res Commun. 2018; 503(2):870-5.

22. Lu HF, Yuan WP, Li M, Huang Q, Liu JP, Li LQ, et al. Properly assessing CD133 as a risk factor for poor prognosis in patients with hepatocellular carcinoma after resection. Tumour biology : the journal of the International Society for Oncodevelopmental Biology and Medicine. 2015;36(7):4937-8.

23. Kong Z, Wan X, Zhang Y, Zhang P, Zhang Y, Zhang X, et al. Androgenresponsive circular RNA circSMARCA5 is up-regulated and promotes cell proliferation in prostate cancer. Biochem Biophys Res Commun. 2017:493(3): 1217-23.

24. Basak GW, Carrier E. The search for multiple myeloma stem cells: the long and winding road. Biology of blood and marrow transplantation : journal of the American Society for Blood and Marrow Transplantation. 2010;16(5): 587-94.

25. Hansen TB, Jensen TI, Clausen BH, Bramsen JB, Finsen B, Damgaard CK, et al. Natural RNA circles function as efficient microRNA sponges. Nature. 2013; 495(7441):384-8.

26. Chang P, Wang F, Li Y. Hsa_circ_0000673 is down-regulated in gastric cancer and inhibits the proliferation and invasion of tumor cells by targetting miR-532-5p. Biosci Rep. 2018;38(5).

27. Liu Y, Lu C, Zhou Y, Zhang Z, Sun L. Circular RNA hsa_circ_0008039 promotes breast cancer cell proliferation and migration by regulating miR432-5p/E2F3 axis. Biochem Biophys Res Commun. 2018;502(3):358-63.

28. Trino S, Lamorte D, Caivano A, Laurenzana I, Tagliaferri D, Falco G, et al. MicroRNAs as new biomarkers for diagnosis and prognosis, and as potential therapeutic targets in acute myeloid leukemia. Int J Mol Sci. 2018;19(2).

29. Zhang K, Guo L. MiR-767 promoted cell proliferation in human melanoma by suppressing CYLD expression. Gene. 2018;641:272-8.

30. Feng Y, Zhang L, Wu J, Khadka B, Fang Z, Gu J, et al. CircRNA circ 0000190 inhibits the progression of multiple myeloma through modulating miR-7675p/MAPK4 pathway. Journal of experimental \& clinical cancer research : CR. 2019;38(1):54.

31. Gregorova J, Vrabel D, Radova L, Gablo NA, Almasi M, Stork M, et al. MicroRNA Analysis for Extramedullary Multiple Myeloma RelapseKlinicka onkologie : casopis Ceske a Slovenske onkologicke spolecnosti. 31(Supplementum1):148-50.

\section{Publisher's Note}

Springer Nature remains neutral with regard to jurisdictional claims in published maps and institutional affiliations.

Ready to submit your research? Choose BMC and benefit from:

- fast, convenient online submission

- thorough peer review by experienced researchers in your field

- rapid publication on acceptance

- support for research data, including large and complex data types

- gold Open Access which fosters wider collaboration and increased citations

- maximum visibility for your research: over $100 \mathrm{M}$ website views per year

At BMC, research is always in progress.

Learn more biomedcentral.com/submissions 